\title{
0 extrato acetônico alcoólico de Timbó e 0 óleo Diesel como inseticidas
}

\author{
Lamartine Antonio da Cunha \\ Assistente Técnico e Docente Livre da 5.a Cadeira \\ Escola Superior de Agricultura \\ "Luiz de Queiroz", Universidade \\ de S. Paulo
}

\section{INDICE}

O extrato acetônico de Timbó na destruição de carrapatos, piolhos, e cura da sarna dos animais domésticos . . . . . . . . . . . 456

Preparo do extrato acetônico .................4 458 Destruição de carrapatos nos bovinos ........... 458
Destruição dos piolhos dos suinos ...............459

Tratamento da sarna dos cães ...............460

Substituição do querozene pelo bleo Diesel nas emulsōes de sabão contra os piolhos dos suinos .........461

Conclusão $\ldots \ldots \ldots \ldots \ldots \ldots, 462$ 
O EXTRATO ACETONICO DE TIMBO NA DESTRUIÇAO DOS CARRAPATOS, PIOLHOS, E CURA DA SARNA DOS ANIMAIS DOMHSTICOS

O velho costume das benzeduras e simpatias, já vai ganhando o terreno do esquecimento, porque qualquer criador, hoje em dia, para combater os males que atingem seus animais, sabe onde reside um veterinário ou onde fica o Instituto Biológico, e mesmo, na sua maioria, sabe vacinar sua criação. Isto, graças a propaganda feita pelos técnicos em Agronomia e Veterinária, hoje espalhados por todos os pontos do nosso Brasil.

Os criadores estão convictos de que náo é económica a exploraçáo da criação dos animais domésticos, mediante os condenáveis métodos dos tempos passados. $\mathbf{E}$ por isso, 0 uso das vacinas preventivas, dos banhos carrapaticidas, dos inseticidas, etc., já ganha terreno, porque diante dos resultados favoráveis obtidos por aquéles que os praticam, os incrédulos terminam cedendo à evidéncia dos fatos e convencem-se de qué devem trilhar a mesma estrada se năo quiserem ter surpreșs desagradáveis.

Temos notado que, de algum tempo para cá, a medicina veterinária não anda satisfeita com os processos e as substâncias empregadas no combate aos diversos parasitos que frequentemente atacam os animais domésticos, porque essas substancias nem sempre produzem os resultados desejados.

No caso da destruiçăo dos carrapatos, que tantos prejuízus cuusam aos nossos animais, verifica-se que nos banhos carrapaticidas, seja pela falsificaçăo das drogas empregadas, seja pela má dosagem ou pela aplicaçáo sem os devidos cuidados, nem sempre se obtem bons resultados, principalmente em de-terminadas regióes do corpo animal, tais como a cabeça, orelhas, etc..

$\mathrm{Na}$ eliminaçăo dos piolhos que frequentemente infestam a porcada, principalmente as raças especializadas, atacando de preferencia a leitoada nova, o emprégo dos banhos à base de petróleo tornou-se um problema de difícil soluçăo devido à talta absoluta dêsse elemento no mercado. Os banhos com infusăo de fumo também tornaram-se impraticávels, năo só devido à escassez, como ao preço elevadíssimo desse produto.

O tratamento das sarnas dos pequenos e grandes animais, para o qual se recorria comumente a pomada de Helmerich, apresenta 0 inconveniente de engordurar o pelo, o que vem deixar o animal em estado lastimável. 
Ainda, além do seu elevado preço, se năo for aplicada convenientemente e repetidas vezes, nzo elimina 0 mal.

A ciencia moderna verificou que certos vegetais possuem substancias tóxicas que sòmente tem açăo sôbre os animais de sangue frio, nåo apresentando perigo algum para 0 homem e demais animais de sangue quente.

Essa nova orientaçáo, apesar de já ter conquistado terreno e existirem laboratórios especializados na preparaçăo de tais inseticidas vegetais, que resolvem satisfatoriamente ta importante problema, ainda se encontra na sua fase inicial. Temos certeza que ela ganhará vulto num futuro mui próximo, quando forem modificados os processos até aqui empregados.

Os vegetais, que a ciência hoje julga descobertos e a indústria procura explorar como inseticidas, fá constituiam o arsenal iquitiotóxico dos nossos aborigenes, o que nos leva a recordar o que afirmava o rei sáblo Salomáo: "Nada existe de novo debaixo do sol".

Os nossos aborigenes foram os descobridores da açáo nociva dos Timbós, que a ciencia e a indústria atualmente aproveitani para a extraçăo de um princípio ativo - a rotenona. âles o.s aplicavam pelo método mais prático e racional, pois em pregavam o material integral e em estado fresco, contra os peixes de todos os tamanhos, que são os maiores animais de sangue frio, e agindo em grandes ambientes.

A palavra timbó é originária do tupí, e quer dizer: ty suco e mboy - cobra, ou, por outra, suco que mata. Pertence à familia das leguminosas e compreende os generos Lonchocarpus, Derris, etc..

Porcentagem do alcalóide existente na planta - As análises até hoje conhecidas demonstram que a porcentagem de alcalóide contida no Derris ellipticus, Benth., quando de muito boa qualidade varia de 2,5 a 6\%, enquanto que nos Lonchocarpus atinge de 7 a $11 \%$.

Os timbós mais ricos em rotenona são os das espécies sarmentosas ou cipoengas. O principio ativo é extraido especialmente das raizes secundárias, isto é, raizes que se formam ao lado da raiz principal. Por êsse motivo, tornam-se necessários certos cuidados na arte de cortar essas raizes, para evitar fevimentos nas principais, o que viria prejudicar a planta.

Desejando contribuir, na medida de nossas fôrças e possibilidades, na campanha da destruição e combate aos parasitos que tantos males e prejuizos causam aos nossos rebanhos, evitando entretanto o acréscimo de despesas com tal campanha, 
fizemos algumas experiências com o extrato acetônico de Timbó, cujos resultados passamos a relatar.

\section{Preparo do extrato acetônico}

Para o preparo do extrato acetônico utilizei um produto pulverizado, vindo há alguns anos do Ministério da Agricultura e destinado ao Prof. N. Athanassof.

A técnica que empreguei para a extração da rotenona fol a aconselhada pelo Dr. J. R. Meyer, do Instituto Biológico de șão Paulo, que, para êsse fim, utiliza a acetona.

Tomei um frasco de bóca larga, coloquei 50 grs. de pó das raizes da planta, juntel 100 cc. de acetona e agitel muito bem. Deixei em maceração pelo espaço de 24 horas. Decorrido êsse espaço de tempo, filtrei e obtive o extrato acetônico de Timbó, de coloraçáo um tanto avermelhada escura.

Para o emprégo nos ensaios, tomei 15 cc. do extrato acetonico e juntel $985 \mathrm{cc}$. de álcool de $42^{\circ} \mathrm{C}$.

\section{Destruição de carrapatos nos bovinos}

1.0 ENSAIO - Em 5-5-1944 notel que as novilhas existentes no Pôsto Zootécnico, e que viviam sóltas na pastagem, estavam muito afetadas pelos carrapatos, principalmente nas orelhas, pescoço, cernelha e nas faces. Nessa data, escolhi as novilhas Defesa, da raça Guernsey, e Capota, da raça Holandêsa.

Essas novilhas foram lavadas com água e sabăo, e estando ainda úmidas, foi feita a aplicação acima, nas partes infestadas.

Decorridas algumas horas, notei que os carrapatos estavam perdendo a sua côr natural e tornando-se marron claro. No dia 6, pela manhã, observel que vários já tinham caido e outros estavam murchos. Em 7, quase todos tinham caido e os poucos restantes estavam mortos.

2.0 ENSAIO - Em 10-5-1944 resolví experimentar a ação dêsse preparado nas vacas que se encontravam estabuladas e também cheias de carrapatos. Entretanto, resolví modificar um pouco a dosagem aconselhada pelo $\mathrm{Dr}$. J. R. Meyer, para a seguinte:

Extrato acetónico de Timbó $\ldots \ldots \ldots \ldots \ldots \ldots \ldots, 25$ cc. Alcool de $42{ }^{\circ} \mathrm{C}$....................... 975 cc. 
Na aplicaçăo foi observado o mesmo processo acima indlcado, isto é, umidecidas prèviamente as regiós escolhidas.

Para esta experimentaçăo escolhi as vacas: - Iolanda, Balisa, Zanga e Rede, da raça holandêsa, e Aurora, da raça Flamenga. A regia escolhida foi a parte externa e interna das orelhas, que se encontravam repletas de carrapatos.

Duas horas após o tratamento, verifiquei que os carrapatos estavam perdendo sua coloração natural. Em 11-5-1944, notei a queda de grande parte, e em 12-5-1944, quase todos tinham caido. Entretanto, tendo verificado que alguns estavam vivos, nesse mesmo dia fiz nova aplicação do medicamento e em nova verificação feita no dia seguinte não encontrei mais nenhum.

\section{Destruição dos piolhos dos suinos}

1.o ENSAIO - Em 30-8-1944, existindo na pocilga do Pôsto Zootécnico alguns lotes de leitões das raças Duroc-Jersey e Hampshire, bastante atacados pelos piolhos, resolvi fazer a experiência de sua destruição pelo extrato acetônico de Timbó.

A fórmula usada foi a seguinte:

Extrato acetônico de Timbó .............. 25 cc.

Alcool de $42^{\circ} \mathrm{C}$...................... $975 \mathrm{cc}$

O primeiro lote tratado compunha-se de 5 leitoas, raça Duroc-Jersey, filhas da porca n. ${ }^{\circ} 238$, nascidas em 21-8-1944 e 2 leitões, raça Duroc-Jersey, filhos da porca n.o 261 e nascidos sm 21-8-1944.

As regioes mais atingidas pelos piolhos eram: cernelha, atrás das orelhas e axllas.

Antes da aplicação do medicamento, fiz umidecer com agua as regiós a serem tratadas e em seguida a aplicaçăo, com o auxilio de uma pasta de algodão embebida no extrato.

Em 1-9-1944 verifiquei que houve queda da maioria dos piolhos e os restantes estavam descoloridos e soltando-se com facilidade. No dia 4, foi feita nova verificação e não encontrei mais piolhos.

No dia 1 de setembro de 1944 foi feito o mesmo tratamentc em 4 machos e 3 fêmeas, filhos da porca Duroc-Jersey n.o 250, os quais estavam bastante atingidos pelos piolhos na cernelha, orelhas, queixais e axilas.

Em 2-9-1944 verifiquei a queda da maioria dos piolhos e no dia seguinte não encontrei mais nada.

Novo ensaio foi feito em 11-9-1944 em 5 leitōes e 4 leitoas, 
fillhos da porca n.o 9 da raça Hampshire e nascidos em 18-81944. Esses leitões tinham piolhos atrás das orelhas, cernelhas e axilas.

$\mathrm{Na}$ aplicação seguiu-se o mesmo processo acima citado. Fiz a verificação em 13-9-1944 e notei que os piolhos tinham caido.

2.0 ENSAIO - Em 20-9-1945, por ocasião do estágio dos alunos do 4.0 ano, e com o fim de verificar se uma solução mais forte de extrato acetónico de timbó poderia provocar alguma irritação, foi feita a aplicação na seguinte dosagem:

Extrato acetônico de Tímbó $\ldots . \ldots \ldots \ldots \ldots \ldots, 20 \mathrm{cc}$.

Alcool de $42^{\circ} \mathrm{C} \ldots \ldots \ldots \ldots \ldots \ldots \ldots \ldots \ldots . .480 \mathrm{cc}$.

Para o ensaio escolheram-se 2 leitões e 3 leitoas, nascidos em 14-7-1945 e filhos da porca Duroc-Jersey n.o 237; 2 leitres e 4 leitoas, filhos da porca Duroc-Jersey n.o 238, nascidos en 24-8-1945. Asses leitões encontravam-se repletos de plolhos.

No dia 21 foi feita a verificação e năo se encontraram mais piolhos e não foi notada qualquer irritação de pele.

\section{Tratamento da sarna dos cães}

1.o ENSAIO - No dia 20 de maio de 1944 fui procurado pelo Snr. José Pavazelli, residente no Bairro de Sto. António (Vila Rezende), para examinar um cachorro de sua propriedade. Esse cão achava-se atacado de sarna sarcóptica. As regióes mais atingidas eram: ventre, axilas e inserção da cauda.

o tratamento dêsse animal consistiu : em primeiro lugar, uma lavagem com água morna e sabăo. Fm seguida, estando as partes doentes ainda úmidas, fiz a aplicaçáo do extrato acetônico de Timbó da seguinte fórmula:

Extrato acetônico de Timbó $\ldots \ldots \ldots \ldots \ldots \ldots, 35$ cc.

Alcool de $42^{\circ} \mathrm{C}$....................... $965 \mathrm{cc}$

Nos dias subsequentes notei o desaparecimento da comichão e aparecimento de escamação. No dia 25-5-1944 fiz novamente aplicação, especialmente nos pontos ainda afetados peios parasitos, e recomendei ao interessado que, no dia 30-5 1944 fizesse nova aplicaçåo do medicamento.

No dia 10 de junho de 1944 examinel novamente o citado cáo e verifiquei que tinham desaparecido tôdas as placas e que os pélos já começavam a aparecer nas regibes tratadas. 
Em todos os ensalos acima referidos, nada de anormal observel nos diversos animais tratados, nem mesmo escamação ou depilaçáo das regioes tratadas, o que vem provar que o extrato acetonico de Timbó é inócuo para os animais de sangue quente.

\section{SUBSTITUIÇAO DO QUEROZENE PELO OLEO DIESEL NAS} EMULSOES DE SABAO CONTRA OS PIOLHOS DOS SUINOS

A importancia dos óleos minerais, torna-se cada vez mais considerável, devido às nossas fontes de consumo dos mesmos, ocasionadas pelas múltiplas aplicaçóes que a ciencia e a técnica vêm introduzindo no campo do trabalho humano. Năo é preciso salientar entre os oleos minerais a importancia dos óleos crús que, pelas suas propriedades, são empregados năo sòmente como combustiveis, mas também como inseticidas, o que virá forçosamente mals aumentar o seu consumo no nosso pais.

Em vista da situaçăo anormal do mercado de importação de petrólco e das consequencias dal resultantes, tornou-se problema sem soluçăo a obtenção de um pouco de querozene, mesmo aquele necessário ao combate às pragas que atacam os animais doméstieos.

Aqui, na pocilga do Posto Zootécnico, sempre se empregou, e com ótimos resultados, no combate à pediculose dos suinos, uma emulsăo feita de acórdo com a fórmula abaixo:

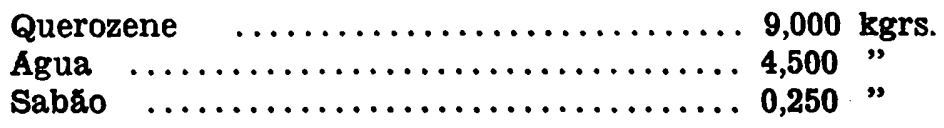

Assim tínhamos a solução mãe, da qual tomávamos 4,500 kgrs. e Juntávamos 40,5 litros de água. Nesta diluição banhavase tóda a porcada e a plolhada era eliminada.

Nestes últimos tempos, grassando a pediculose na porcada, principalmente nos de raças aperfeiçoadas, e náo tendo conseguido pelo motivo acima mencionado o querozene necessário, tendo obtido alguns kgrs. de oleo Diesel, por gentileza do colega Dr. Cyro Marcondes, verifiquei a riqueza dêsse óleo em querozene, e tomei a resoluçăo de experimentá-lo em substituiçăo.

1.0 ENSAIO - Em 5-9-1944 separel numa báia o varrasco Hampshire n.o 50 e a leitoa n.o 37, nascidos em 8-4-1944, am- 
bos bastante atacados pelos piolhos, nas regiбes da cernelha, atrás das orelhas, entre as máos e pernas.

Com o auxilio de um pano embebido no óleo fiz uma leve massagem nas regioes acima citadas.

No dia seguinte, fiz a verificação que os piolhos tinham desaparecido, porém, notel algumas irritaçరes nas regiøes dc pele mais fina, o que me fez supor terem sido produzidas pelo oleo.

2.0 ENSAIO - Em 18-9-1944 o varrasco Duroc-Jersey n.o 242, nascido em 11-8-1940, encontrava-se bastante atacado pelos piolhos.

Nesse varrasco fiz uma aplicaçăo do óleo na seguinte forma:

Óleo Diesel 2 partes

Oleo de algodåo ...................... 1 parte

No dia seguinte verifiquei que os piolhos tinham desaparecido e náo notei irritação alguma nas regiбes medicadas.

3.0 ENSAIO - Em 20-9-1944, diante dos resultados acima descritos, resolvi preparar a formula seguinte:

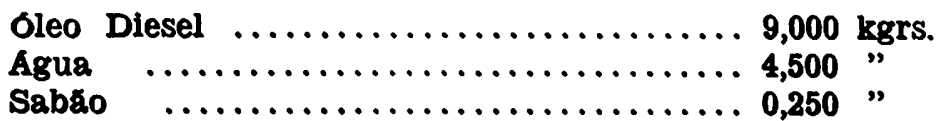

Dessa solução măe, tomei 4,500 kgrs. e adicionel 40,500 kgrs. de água e mandel banhar a porcada toda, isto é, grandes e pequenos.

Feita a verificaçăo no dia seguinte, os porcos năo acusavam presença de piolhos.

4.o ENSAIO - Em 30-8-1945 a porca n.o 27, da raça Duroc-x Canastrăo, nascida em 26-4-1944, apresentou-se com uma eczema na paleta esquerda. Examinada cuidadosamente, verificou-se que era consequencia da enorme quantidade de piolhos. Fez-se a tosquia da regizo e passou-se óleo Diesel. Verificou-se no dia imediato que os piolhos tinham desaparecido e alguns dias depois começou a cicatrizaçăo geral, sem aplicaçăo de qualquer outro medicamento.

\section{CONCLUSAO}

Pelas resultados verificados nos ensalos acima referidos, podemos concluir o seguinte: 
1) - O extrato acetónico alcoblico de Timbó, mesmo em proporçăo mais elevada que aquela aconselhada pelo Técnico do Instituto Biológico de São Paulo, năo prejudica a saúde e a pele dos animais domésticos tratados.

2) - Que, quando aplicado com a técnica e culdados acima referidos, esse inseticida destroi os carrapatos dos bovinos e equinos, e os piolhos dos porcos e cura a sarna dos cães.

¡) - Que năo será economico subsuituirem-se totalmente os banhos arsenicais carrapaticidas pelo extrato acetonico de Timb6, porque este é de preço mais elevado.

4) - Que, como inseticida, o extrato acetonico alcoblico de Timbó é bastante eficiente e de fácil aplicaçáo, podendo ser aplicado em animais pequenos e parcialmente nos grandes animais, nas regibes como a cabeça e orelhas, regibes estas que nem sempre săo atingidas pelos banhos carrapaticidas.

5) - O óleo Diesel poderá também ser usado, tanto na destruiçáo dos piolhos como dos carrapatos, porém, tomando-se certa precauçăo, isto é, adicionado de certa porcentagem de óleo de caroço de algodźo, pois do contrário poderá prejudicar a pele dos animais.

6) - Que o bleo Diesel substitui vantajosamente o querozene no preparo das emulsбes de sabro para combate aos piolhos dos suinos, nao prejudicando a pele e parece que tem aça mais duradoura.

Finalmente, devemos lembrar que a indústria nascente cos inseticidas, principalmente vegetais, precisa ser orientada e amparada pelos poderes públicos, e que o seu sucesso depende da colaboração dos técnicos, experimentadores e de todos \&queles que se interessem pela grandeza da Pátria. 